\title{
Study on Creative Features of Liu Degong's Poems of the Memory Ancient of Twenty-one Capitals
}

\author{
LIU Qingtao \\ College of Liberal Arts, Baicheng Normal University, Baicheng 137000, China \\ email:273168351@qq.com
}

\begin{abstract}
Keywords: Liu Degong; Poems of the Memory Ancient of Twenty-one Capitals; Creation Characteristic
\end{abstract}

\begin{abstract}
Poems of the memory ancient of twenty-one capitals are the Liu Degong's representative, who is representative personage of Korean Northern School. Forty-three poems mainly describe the Korean ancient capital, the king, generals and ministers, which also involve many North Korean ancient legends and folk origin and have a very high literary and historical culture value. Poems of the memory ancient of twenty-one capitals have unique characteristics in the words use and description skill, which mainly embodied in clever choice of words, the use of reduplicated words in the use of words and mainly inspired and allusions in the description technique.
\end{abstract}

\section{Introduction}

Liu Degong, whose courtesy name huifeng, huipu and literary name lingzhai, guyuntang, who is the ancient Korean famous writer and historian in the mid eighteenth century to early nineteenth century, and is representative personage of Korean Northern School.

"Luan Yang record" and "Yan Taiwan tour again" are very famous in Degong Liu's works, which records his two mission to China and the Chinese knowledge as well as their communication with China anecdotes. In addition to literature, Liu Degong also wrote historical works "Bohai investigate", which won the industry attention. Although the creation of Liu Degong is variety, but the best is poetry. His poems are numerous, which mostly are included in "lengzhai collected works", of which poems of the memory ancient of twenty-one capitals is Liu Degong's good work. He is proud of this collection of poems, and often serve poems as gifts for friends. "Luan Yang record" noted that Liu Degong sended the poems to Ji Xiaolan as a gift, "I gave the poems to Ji Xiaolan and he sent me and CiXiu hispoems", which sufficiently showed his awareness of this poems. Ji Xiaolan appreciated Liu Degong's poems very much and thought his work very spiritual and good enough with Cixiu's poems, and he admired Liu Degong [1].

Poems of the memory ancient of twenty-one capitals all seven-character quatrain, which rhyming verse with strict rules and read readabilitily, and which mainly describe the Korean ancient capital, the king, generals and ministers, which also involve many North Korean ancient legends and folk origin and have a very high literary and historical culture value [2]. Poems of the memory ancient of twenty-one capitals have a good quality on creation and its characteristic is distinctive, which deeply reflect the Sinology level of the ancient Korean poets. In general, the unique characteristics of poems of the memory ancient of twenty-one capitals were mainly embodied in two aspects: words and description of methods.

\section{The Clever Use of Words}

Forty-three poems, many poems in words is very clever, which makes the poetry itself has a lot of good statements. In his poems, Liu Degong pays much attention to word selection, especially the selection of the verb.

In the paper of Koguryo [3], the first poem wrote that millennium domineering was cooler than the water, the white jade whip was buried in the cemetery, where the choice of the word "cool" is very typical. "Cool" bought strong feelings to people in reading, where there formed a strong contrast between "millennium domineering" and "cooler than water", make people have infinite 
emotion.

In the paper of Xinluo [4],the first poem wrote that Jinhan confederacy had six countries that are flourishing and the three families near the sea existed for one thousand years. The word "Dan" is very typical in the use that means quietness and peaceful. In the early Chinese literary creation, the word "Dan" was widely applied to the poems because of its meaning. Such as Caocao's poems "Sea View" wrote that going east and climbing the Jishi mountain for watching the vast sea, water quietly flowing, the mountains and islands very steep. The poem "water quietly flowing" refers to the water flow quietly look. Liu Degong in the poems using the word "Dan" not only expressed natural scenery feeling, but also contains a form of Xinluo national culture thinking. History shows that Xinluo was established in a stable and peaceful state, unlike Goguryeo and Baekje had experienced a number of war to be established. By the visible on, Liu Degong should be fully considered the factors in the state of Xinluo in poetry creation, only a "Dan" word is not only the performance of the full description of the sparse light smoke scene, but also a metaphor for the state formation in the peaceful environment of cultural history.

Liu Degong in poems of the memory ancient of twenty-one capitals paid full attention to the conversion of words in grammar to verse effects in addition to pay attention to words. In the paper of weiman Korea, Liu Degong wrote that it can't compare with the women who played a song with konghou amazing millennium [5].The adjective "Yan" is used as a verb in this poem, and is transferred as amazing millennium. The author made the poem have a dynamic sense of color with the way using the adjective as the verb, at the same time that causes the reader's attention by the way of the verb in advance, so as to highlight the artistic effect of the poem.

Readers in the reading process firstly saw the word "Yan", which made the readers have a bright feeling in an intuitive sense to read and took a pause for the change of words to make people produce profound impression and can not be forgotten to linger in verse. This method of constructing poetry by converting the grammatical properties of words is the method of defamiliarization. Defamiliarization is a very important theory in the study of formalism in Russia. This theory holds that the basic purpose of literary creation lies not in aesthetic purposes, but in the aesthetic process. They think that when people perceive what they are familiar with, they tend to perceive themselves automatically. This automatic perception is the result of the old form. To make automatic perception turn into aesthetic perception, we need to adopt "Defamiliarization" means, create new art forms, let people liberate from automatic perception, and appreciate the original things again aesthetically. A writer should try to prolong the process of aesthetic perception. Liu Degong in a verse of the words in the deformation process, achieved the effect of defamiliarization well .

In addition to pay attention to the choice of words and grammatical deformation, Liu Degong was very good at the use of reduplicated words to create a poem. This kind of usage was found everywhere in "poems of the memory ancient of twenty-one capitals". Liu Degong with a way of using reduplicated words widely organized the verse, and often reflected in the description of natural scenery. The use of reduplicated words made the poems produce a distant sense of artistic conception, which made the scenery described having dynamic properties. Such as "rock flowers falling, water long", it gives people a feeling of static movement, water flows regardless of time, day and night, everything in the universe in this long flowing water passing which Not only gives a strong aesthetic experience, but also gives people a profound philosophical thinking.

\section{The Description Ploy of Stimulants and Allusions}

Stimulants is to say that describing something else and then describing others, which is often used in poetry or the festival begins and is an artistic expression using language factors based on statement with help with of the things to express the feelings. This description ploy not only can serve to create works atmosphere, coordination of rhythm, rhyme and determine the foot, twist even the context of the role, but also can make the language chant free and poems lively. In the poems of the memory ancient of twenty-one capitals, Liu Degong mostly used the "stimulants" description. Liu Degong in poems generally described scenery firstly on the description of the history, and then 
pointed out the historical content written. These begins with the description of the scenery seems beside out the point, but in fact that can be very good for the expression of the theme and play a foreshadowing role. This description way is actually the "stimulants", which first said other things, then with the theme. Such as the paper of Koguryo, the former two lines described the scenery mainly, seemingly simple description of scenery, but the last lines changed the theme and described Kaogouli's Eulji mundeok's heroic deeds. The former two lines well render the theme of this poems and lay a solid foundation for the narrative tone of the last two. This description of the former two lines gave a very open mind, backed the formation well with the following general Eulji mundeok's brilliant heroic deeds.

The stimulants way used in the poems by Liu Degong in some extent was not large scale and the former lines have some degree of association with themes to content description mostly. As you can see, the scene from the opening paragraph about the geographical environment in poems of the memory ancient of twenty-one capitals are all related to the history. For example, the first poem of the paper of Jizi Korea and the first of the paper of Weiman Korea, from the two poems, we can see that the description of the first sentence is closely related to the historical content of the theme.

"Allusion" is another important description way used in Liu Degong's poems of the memory ancient of twenty-one capitals [6].The so-called allusion refers to the historical stories or quoted words in ancient books to illustrate a rhetoric of their views. The allusion is divided into two kinds of dark and light. Every in poems of the memory ancient of twenty-one capitals almost used "allusion", that was because the poem itself was meditated on the past, and was a kind interpretation again of literature of ancient history and legend, which was inevitable to make the allusion and the narrative be confused. Or we may think that poems of the memory ancient of twenty-one capitals were reinvention of literature of historical allusions. The allusions used in poems of the memory ancient of twenty-one capitals by Liu Degong can be divided into the following three types:

First of all, the allusions to the formation of ancient Korean countries. In poems of the memory ancient of twenty-one capitals, Liu Degong referred to allusions about the formation of Dangun Joseon era, and pointed out that the historical facts that Korea was established by Dangun Wang Jian.

Second, the allusions to historical figures of ancient Korean. In poems of the memory ancient of twenty-one capitals, many representative historical figures were described, these historical figures were well known because of their historical deeds, Liu Degong expressed his thoughts on history by reference to these historical figures. The third poem of Koguryo paper described the historical period of the king Ping Gang in the Goguryeo by introducing the image of Wenda. Similarly, the fourth poem of Xinluo paper used an allusion to Xinluo celebrity Cui Zhiyuan.

Third, the allusions to the ancient Korean legend. The ancient legends of Korea are very rich that have gradually become an important part of history in the long process of development and absorbed people's interest. There were many poems describing the more distinctive legends of different historical periods in poems of the memory ancient of twenty-one capitals. In Mingzhou paper, a pair of young men and women of the legendary love was described. The poet ingeniously connected the history with legend about Mingzhou, that made the poems have infinite historical and cultural connotation in the simple narration.

\section{Conclusion}

The poems of the memory ancient of twenty-one capitals are outstanding chapters describing the ancient Korean history, that have shown superb artistic level of Liu Degong from words to description and is the classical work of classical Chinese poems creation in Korea.

\section{References}

[1] Jin Fushi. Samguk Sagi. Kyujanggak's revised edition.

[2] Yi Ran. Samguk Yusa. Changsha: Yulu Press, 2009. 
[3] Huang Chunjiu. Korean hanwen narrative poems anthology. Seoul:Taixue Society, 1984.

[4] Zhu Liyuan. Contemporary western literary theory. Shanghai:East China Normal University Press, 2003.9.

[5] Zhang Bowei. Research on the method of ancient Chinese literary criticism. Beijing: Zhonghua Book Company, 2002.

[6] Li Yan, Xu Jianshun. Comprehensive history of Korean literature. Beijing, Social Sciences Academic Press, 2010. 